\title{
Paisagens Tipográficas Pelotenses: levantamento inicial do acervo e algumas definições metodológicas
}

\author{
Typographic Landscapes of Pelotas: initial survey of the \\ collection and some methodological definitions
}

tipografia; design da informação; paisagem urbana; cultura. typography, information design, urban landscape, culture
Este artigo apresenta parte do desenvolvimento da pesquisa Paisagens tipográficas pelotenses: estudo exploratório sobre a tipografia no espaço urbano. O estudo tem como objetivo investigar as diferentes ocorrências de paisagens tipográficas em determinadas regiões urbanas da cidade de Pelotas/RS visando uma melhor compreensão da tipografia enquanto informação histórica e cultural. A investigação toma por base alguns estudos sobre as 'paisagens tipográficas' que vêm sendo desenvolvidos nos últimos anos em várias cidades brasileiras, os quais apontam uma série de métodos para coleta, tratamento e análise de dados concernentes à tipografia no espaço urbano. Sendo assim, a metodologia adotada baseia-se nas indicações de processos investigativos já iniciados neste campo, tais como o estabelecimento de rotas e fichas de pesquisa de campo, engendrando adaptações necessárias ao contexto em questão. O presente artigo, a partir da contextualização da pesquisa, apresenta amostras do levantamento de duas categorias tipográficas realizado em região específica, além da adaptação proposta para a estruturação da ficha de catalogação e análise.

This paper presents part of the research "Pelotas Typographic Landscapes: An exploratory study of the typography in the urban space". The study aims to investigate the different occurrences of typographic landscapes in certain urban areas of the city of Pelotas / RS to better understanding of typography as a historical and cultural information. The research is based on studies of 'typographic landscapes' that have been developed in recent years in several Brazilian cities, which presents methods for collecting, processing and analysis of typography data in the urban space. Therefore, the methodology adopted is based on the indications of investigative process already started in this field, such as the establishment of routes and field research records, making adaptations necessary to context. This paper presents samples of survey from two typographical categories performed in a specific region, in addition to the proposed adjustment to the structure of cataloguing and analysis record. 


\section{Introdução}

Este artigo apresenta alguns resultados parciais da pesquisa "Paisagens Tipográficas Pelotenses: estudo exploratório sobre a tipografia no espaço urbano", realizada na cidade de Pelotas, no Estado do Rio Grande do Sul, região sul do Brasil. A referida pesquisa tem como objetivo investigar as diferentes categorias de paisagens tipográficas em determinadas regiões urbanas da cidade de Pelotas visando uma melhor compreensão da tipografia enquanto informação histórica e cultural.

A história e cultura de um lugar estão impressos em seu patrimônio material e imaterial. Os prédios e monumentos de uma cidade são exemplos de patrimônio material responsáveis por deter o tempo impedindo que o passado se perca no esquecimento, tornando-os o que se pode entender por 'lugares de memórias' (Nora, 1993). Também os elementos gráficos, tal como aponta Lynch (1997) são, dentre outras coisas, formadores da identidade visual, estética e cultural das cidades, funcionando tanto como indicadores de fluxos urbanos e processos de wayfinding (Gibson, 2009), quanto como "marcos que identificam e nomeiam pontos da cidade, auxiliando na definição de sua estrutura informacional”. (Gouveia, Farias, Pereira \& Barreiros, 2007: 2).

Além disso, os usos, costumes e características próprias de um determinado contexto cultural podem fornecer informações importantes para o desenvolvimento de projetos orientados à inovação. Para além do revivalismo ou da estagnação da cultura material, essa perspectiva promove o reconhecimento desta herança cultural e incentiva o designer a "investigar as possibilidades de incorporação de aspectos característicos da sua identidade cultural, utilizando-os como ponto de partida para novas ideias, tendências e objetos" (Guterrez, 2011).

O espaço urbano é, assim, permeado por letras, números e sinais que constituem sua 'paisagem tipográfica' e que podem ser entendidos como parte do discurso semiótico e identitário das cidades. Tipografia, neste contexto, deve ser entendida em sentido amplo, abarcando diferentes processos de criação e reprodução, em diferentes formas e suportes (Farias, 2001; Gouveia, Farias, Pereira \& Barreiros, 2007; Baines \& Dixon, 2003).

Deste modo, considera-se que essas paisagens e elementos tipográficos devam ser reconhecidos como característicos e importantes na composição do patrimônio material da cidade. Da mesma forma que as edificações e os monumentos, estes marcos tipográficos materializados na forma de placas de ruas, tampas de bueiros, inscrições em placas comemorativas, inscrições arquitetônicas nominativas ou monogramas em platibandas de edifícios - constituem um acervo significativo e representativo no conjunto urbano. 
1 O projeto "Memória Gráfica de Pelotas: 100 anos de Design", originalmente denominado "Memória Gráfica: in/ex pressões em resgate", foi idealizado, em sua primeira versão, pela autora/ coordenadora da pesquisa apresentada neste artigo, professora Daniela Brisolara, juntamente com a professora Ana Bandeira, quando ambas exerciam atividades docentes no curso de Design Gráfico do Instituto de Artes e Design (hoje Centro de Artes) da UFPel (BANDEIRA \& BRISOLARA, 2010). Em versão ampliada e atualizada e constituído por um grupo de pesquisa orientado às ações de preservação e conservação de documentos de perfil histórico, o projeto Memória Gráfica de Pelotas: 100 anos de Design, "propõe identificar, categorizar e analisar as fontes bibliográficas e respectivos dados sobre $o$ desenvolvimento do Design Gráfico em Pelotas durante o século XX a partir das fontes de periódicos impressos locadas no Acervo da Bibliotheca Pública Pelotense, organizando seus respectivos resultados em artefatos impressos e eletrônicos que garantam a guarda dos seus originais e respectivo acesso das informações sobre o desenvolvimento do Design local" (Fonte: http:// www2.ufpel.edu.br/iad/ memoriagraficadepelotas/ sobre.htm).
Levando-se em conta a ideia de detenção do tempo ou bloqueio do esquecimento, é interessante observar que estes elementos incrustrados na cidade, no caso de Pelotas, em geral reforçam a idenficação com um período, que diz respeito àquele considerado de maior desenvolvimento e abundância econômica da cidade. Assim, serão encontrados registros tipográficos especialmente em casarões ecléticos do século XIX e elementos urbanos e edificações do início do século XX, períodos que demarcam a pujança da sociedade pelotense e as características da identidade cultural de influência européia (Langone, 2012).

Mas como se mostra o conjunto desses elementos na cidade? Quais os métodos de análise dessas formas urbanas? É possível identificar outros estilos e valores? Este tipo de questionamento norteia a pesquisa aqui apresentada, cujos dados gerados devem evidenciar essas ocorrências tipográficas e sua história, além de permitir a identificação de especificidades culturais e a comparação de casos em locais e tempos diferentes.

Neste intuito, a investigação se pauta em estudos sobre as 'Paisagens Tipográficas' que vêm sendo desenvolvidos nos últimos anos em várias cidades brasileiras, tais como os projetos 'Tipografia Arquitetônica Paulistana', 'Paisagens Tipográficas', 'Tipografia Arquitetônica Carioca' e 'Memória Gráfica Brasileira', os quais apontam uma série de métodos para coleta, tratamento e análise de dados concernentes à tipografia no espaço urbano, como o estabelecimento de rotas e fichas de pesquisa de campo (GOUVEIA et al, 2006; Farias, Gouveia \& Solomon, 2009; Langone, 2012).

\section{Antecedentes}

Em Pelotas/RS, o projeto "Memória Gráfica de Pelotas: 100 anos de Design" tem investigado o desenvolvimento do design gráfico impresso na cidade, gerando protocolos de pesquisa específicos e pertinentes ao estudo da tipografia e seus aspectos memoriais. Também um estudo piloto realizado em Pelotas/RS (Langone, 2012), com enfoque na tipografia arquitetônica nominativa, é tomado por base da presente proposta, sinalizando alguns caminhos metodológicos. Outra iniciativa, a partir de uma atividade de ensino na disciplina de Tipografia, do curso de Bacharelado em Design do IFSul - Campus Pelotas, procurou delinear as primeiras impressões sobre a 'paisagem tipográfica pelotense', realizando registro fotográfico de diferentes categorias (situadas em regiões centrais delimitadas), mas ainda sem catalogação ou análise. 


\section{Metodologia da pesquisa}

\section{Categorias de paisagem tipográfica}

A pesquisa considera as diferentes categorias de 'paisagens tipográficas' determinadas por Gouveia \& Farias (2007; apud Gouveia, Farias, Pereira \& Barreiros, 2007: 3), as quais seriam formadas por tipos diversos de inserção, evidências históricas e com diferentes tipos de permanência, a saber:

1. Tipografia arquitetônica: inscrições perenes, tais como o nome e o número de um prédio, geralmente planejadas e construídas junto com o edifício;

2. Tipografia honorífica: inscrições projetadas para homenagear personagens ou fatos históricos relevantes tais como aquelas presentes em monumentos públicos em geral.

3. Tipografia memorial: inscrições fúnebres encontradas em espaços urbanos circunscritos, tais como lápides em igrejas ou cemitérios.

4. Tipografia de registro: inscrições oficiais de empresas públicas ou privadas, tais como prestadoras de serviços de telefonia e saneamento, geralmente localizadas em grades e tampas.

5. Tipografia artística: manifestações artísticas realizadas sob encomenda, que fazem uso da tipografia, tais como pinturas e esculturas em formato de letras, presentes em algumas cidades.

6. Tipografia normativa: inscrições que configuram sistemas reguladores e informativos do tráfego urbano, tais como sinais de trânsito e placas de logradouro;

7. Tipografia comercial: inscrições efêmeras, tais como aquelas presentes em pontos comerciais, acrescentadas posteriormente aos edifícios, e, na maioria das vezes, substituída periodicamente;

8. Tipografia acidental: inscrições não-oficiais ou nãoautorizadas, tais como grafites e pichações, muitas vezes executadas sem planejamento e à revelia da vontade dos arquitetos, construtores e proprietários dos edifícios.

\section{Escopo da pesquisa e zonas de investigação}

Dentro do escopo da presente investigação, nesta primeira etapa da pesquisa, são consideradas apenas as categorias de inscrições perenes (números 1, 2, 3, 4 e 6), trabalhando 2 destas categorias - Tipografia Arquitetônica e Tipografia de Registro. A abrangência geográfica da pesquisa foi definida a partir das 4 (quatro) Zonas de Preservação do Patrimônio Cultural - ZPPC (figura 1) determinadas pela lei municipal no ${ }^{0}$ 4568/200 que busca manter a integridade de espaços urbanos com características históricas e culturais importantes. As rotas para o levantamento dos dados foram definidas a partir de um levantamento fotográfico piloto percorrendo as ZPPCs. 
Pelo fato do centro urbano de Pelotas ter surgido no entorno da Praça Coronel Pedro Osório, esta é a região com maior relevância patrimonial, a ZPPC 2. No entanto, foi constatado, em estudo de campo piloto, que há registros tipográficos importantes em outras regiões, tornando-se indispensável uma demarcação de rotas mais abrangentes (figura 2). O grupo percorreu as rotas por 3 dias fazendo o levantamento dos dados e registro fotográfico. Após observação dos resultados, optou-se pela definição, não de rotas demarcadas em determinadas ruas, mas pela 'varredura' geral das ZPPCs, abarcando sua totalidade. Sendo assim, o grupo realizou o levantamento e o registro fotográfico dos dados encontrados em campo, percorrendo todas as ruas de cada uma das ZPPCs.

Figura 1 Zonas de Preservação do Patrimônio Cultural. (Fonte: Material desenvolvido pelo grupo de pesquisa a partir do acervo da SECULT).

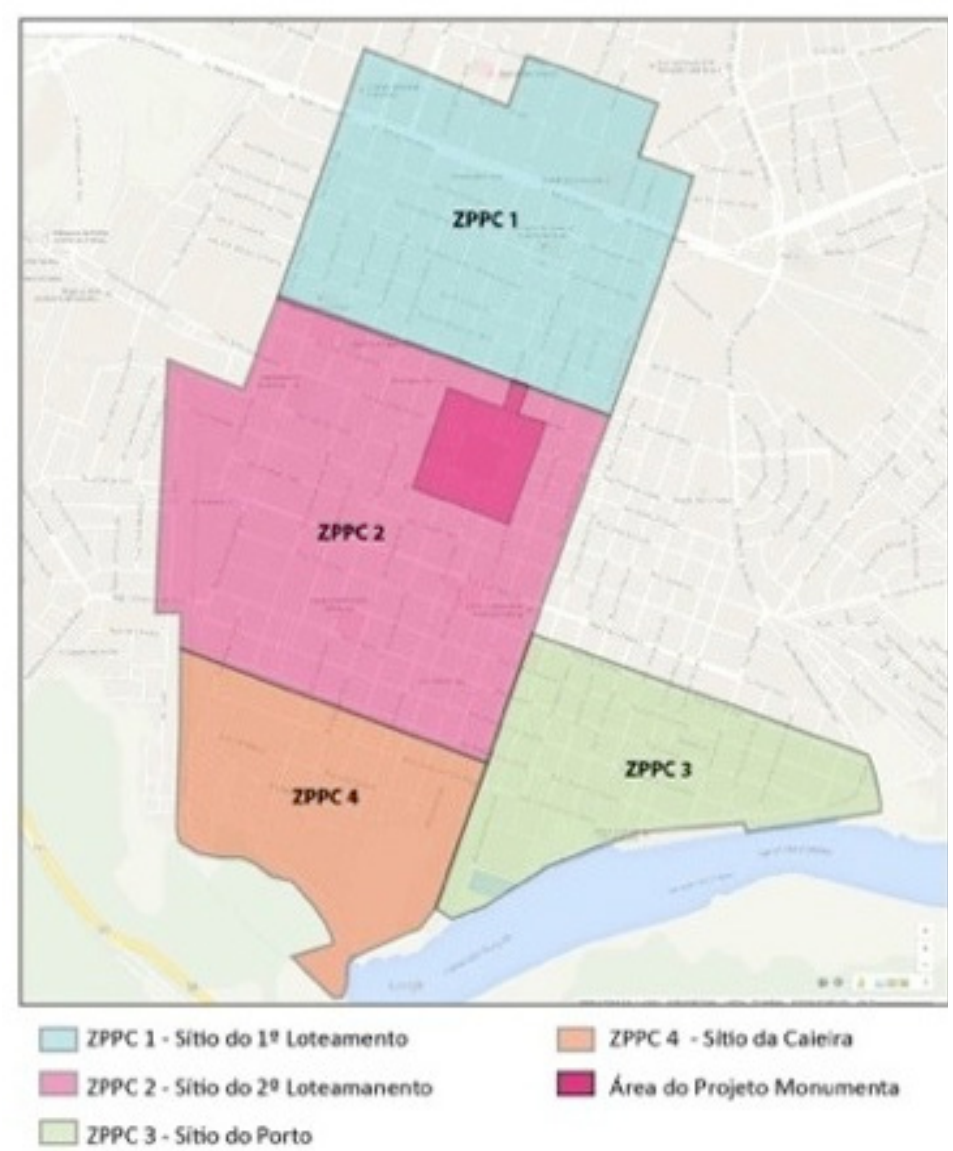


Figura 2 Rotas de levantamento das tipografias de cada dia. (Fonte: Material desenvolvido pelo grupo de pesquisa a partir do acervo da SECULT).

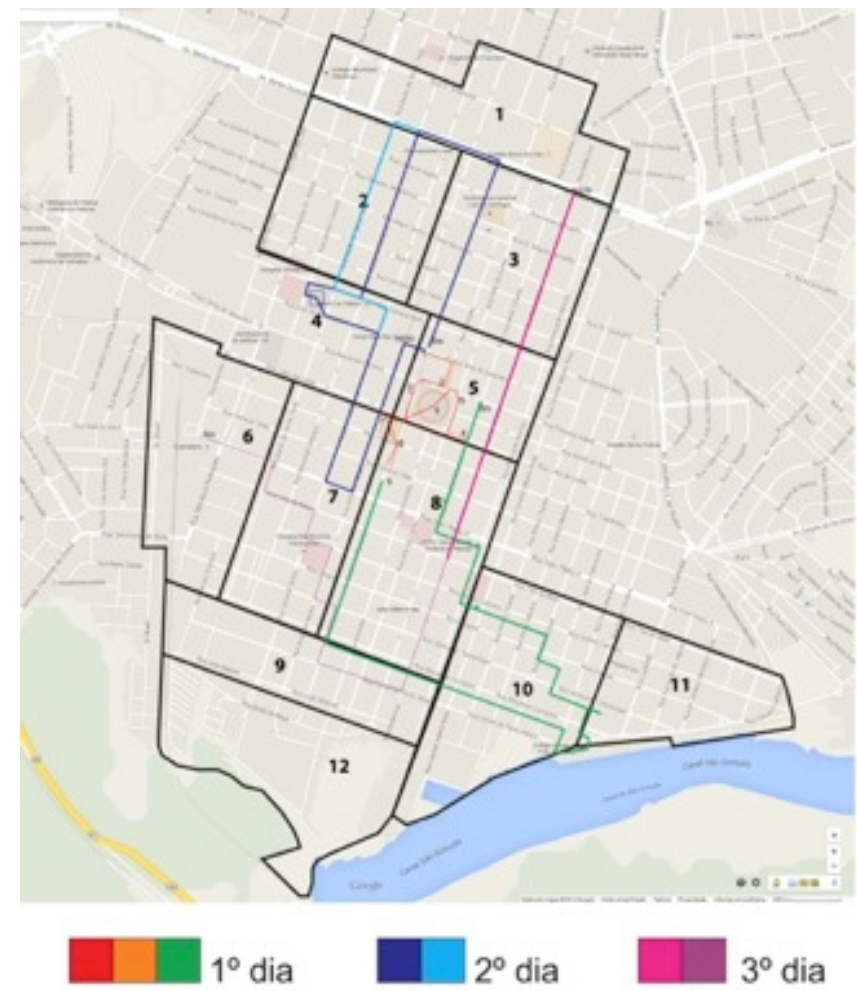

Na primeira etapa da investigação o enfoque da pesquisa é voltado a duas categorias específicas de tipografias perenes, a Tipografia Arquitetônica e a Tipografia de Registro. Abaixo seguem alguns registros fotográficos de tipografias arquitetônicas, encontradas em fachadas de prédios históricos (figuras 3, 4, 5 e 6) e inscrições de tipografia de registro encontradas em tampas das redes de esgoto e telefonia, nas ruas de Pelotas (figuras 7, 8 e 9).

Figura 3 Inscrição da fachada do Mercado Público. (Fonte: Acervo da pesquisa)

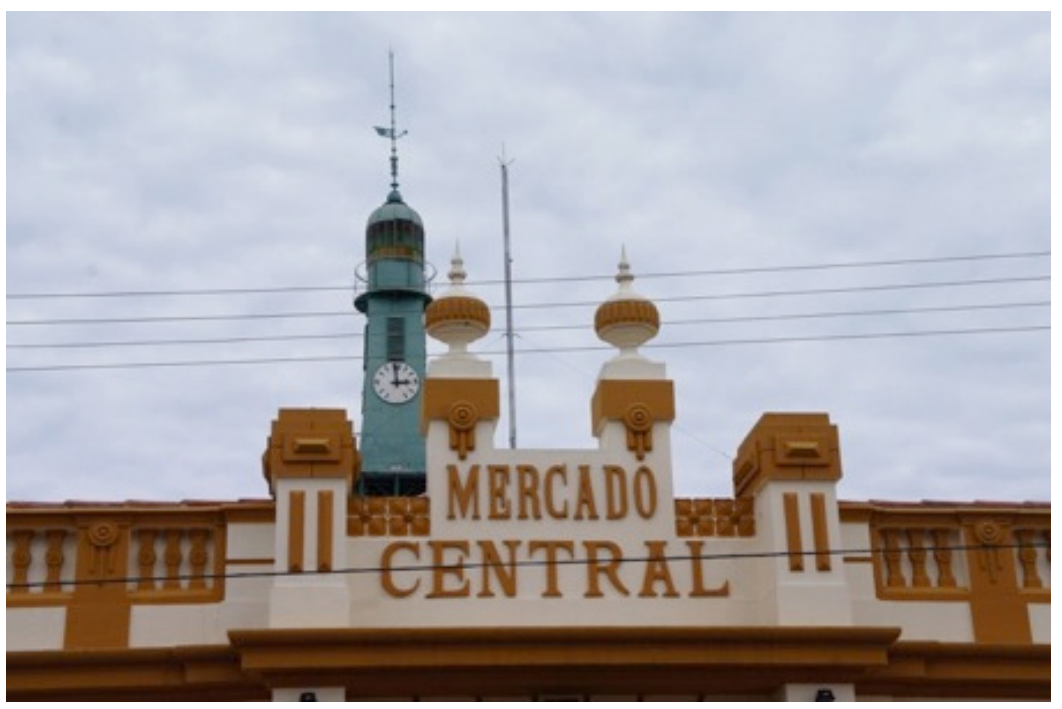


Figura 4 Inscrição da fachada do Teatro Guarany. (Fonte: Acervo da pesquisa).

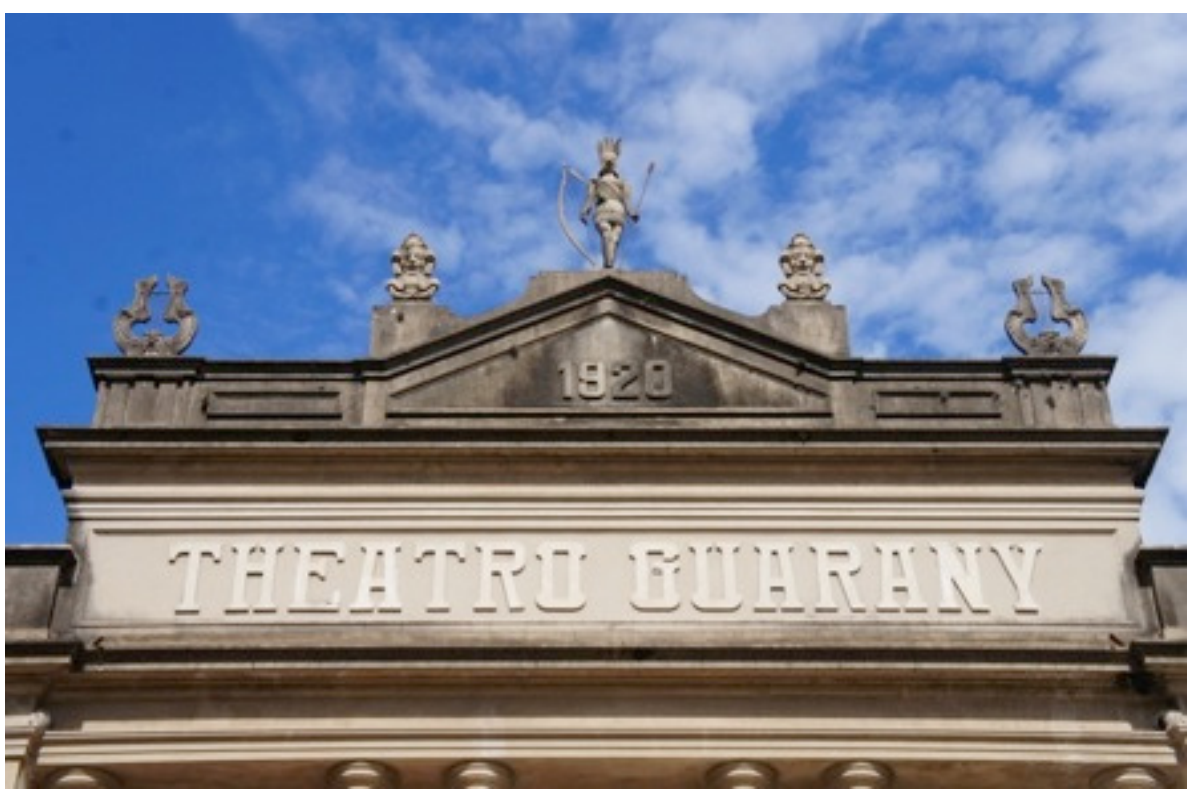

Figura 5 Monograma e numeração em fachada de prédio histórico. (Fonte: Acervo da pesquisa).

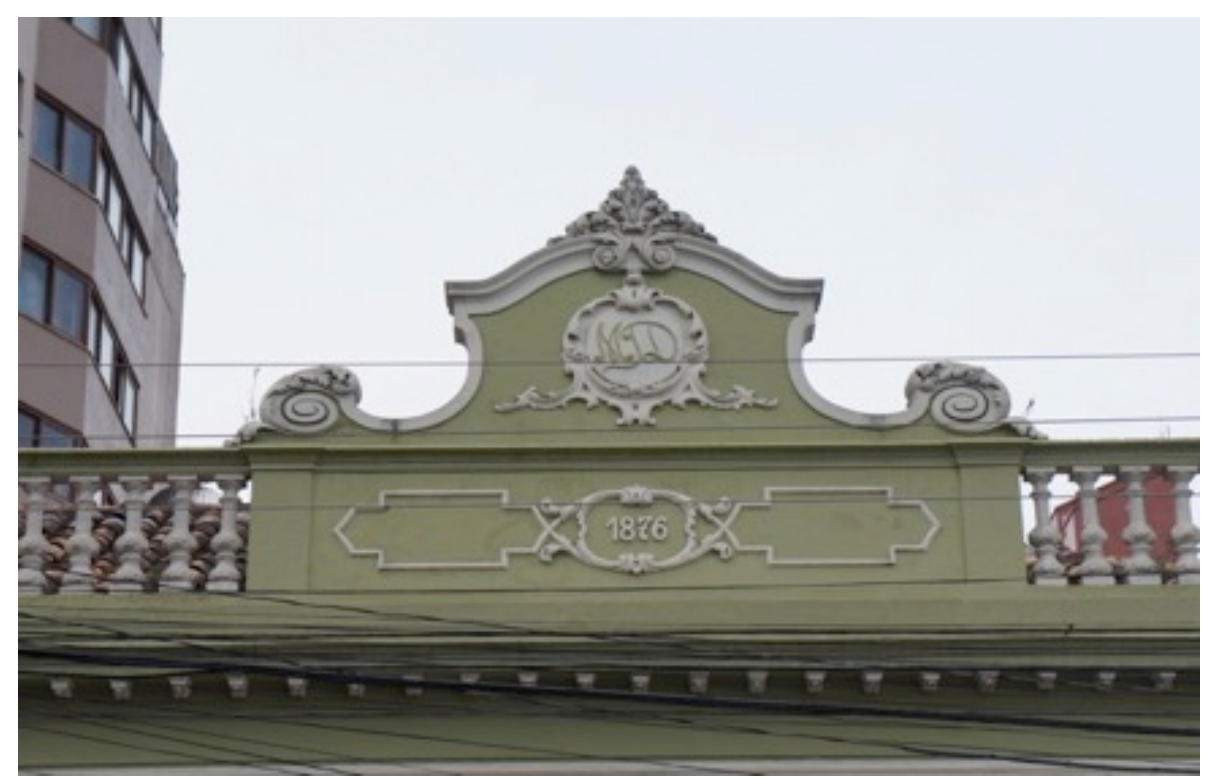


Figura 6 Tipografias arquitetônicas - Pelotas. ( Fonte: Acervo da pesquisa).

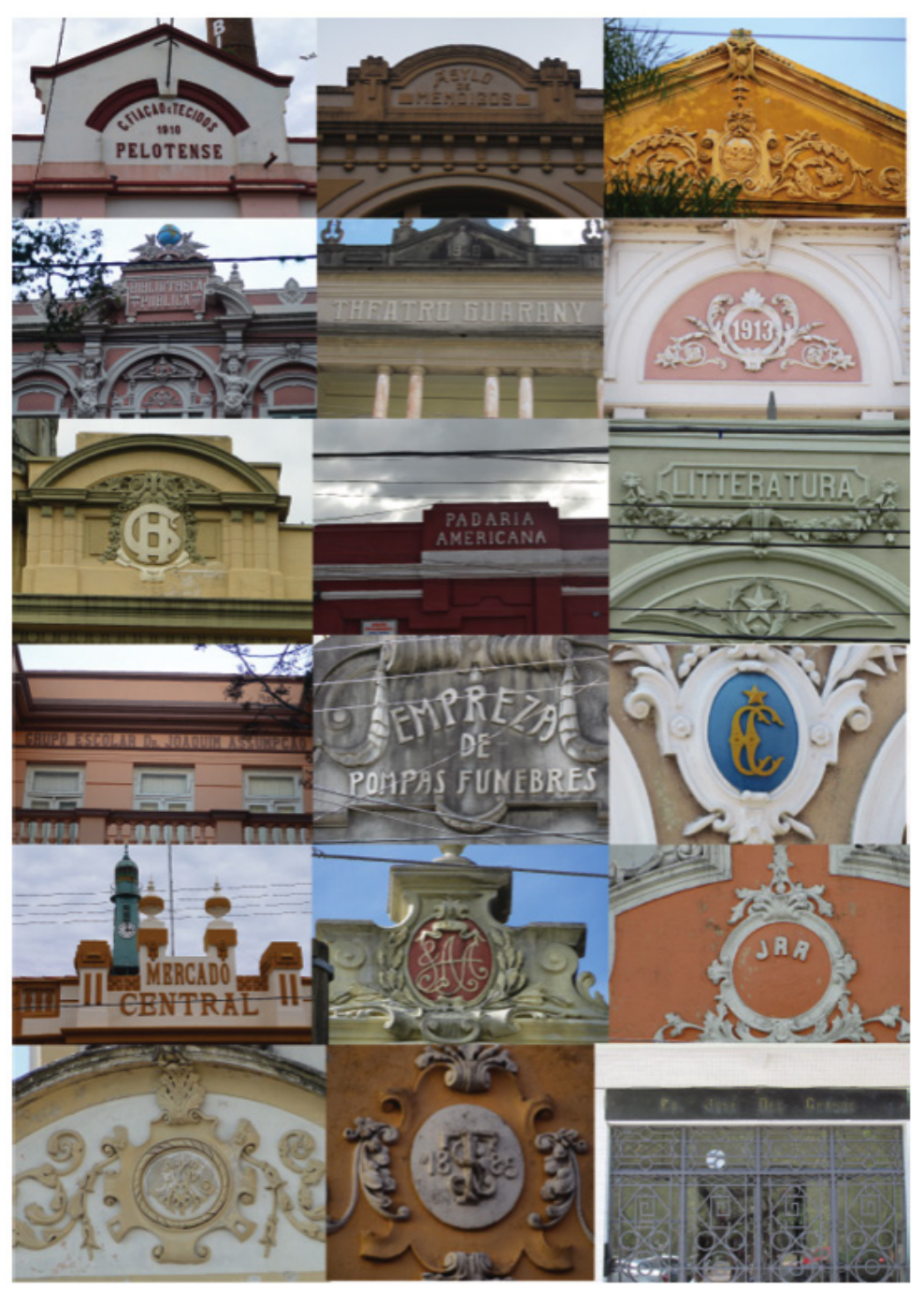

Figura 7 Inscrição em tampa de esgoto. (Fonte: Acervo da pesquisa)

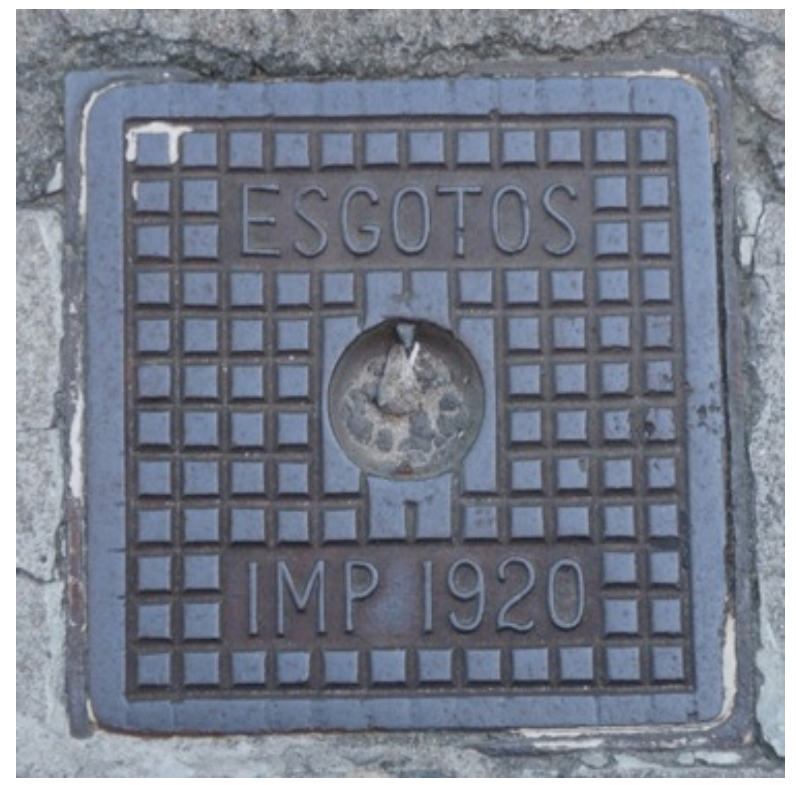


Figura 8 Inscrição em tampa de esgoto. (Fonte: Acervo da pesquisa).

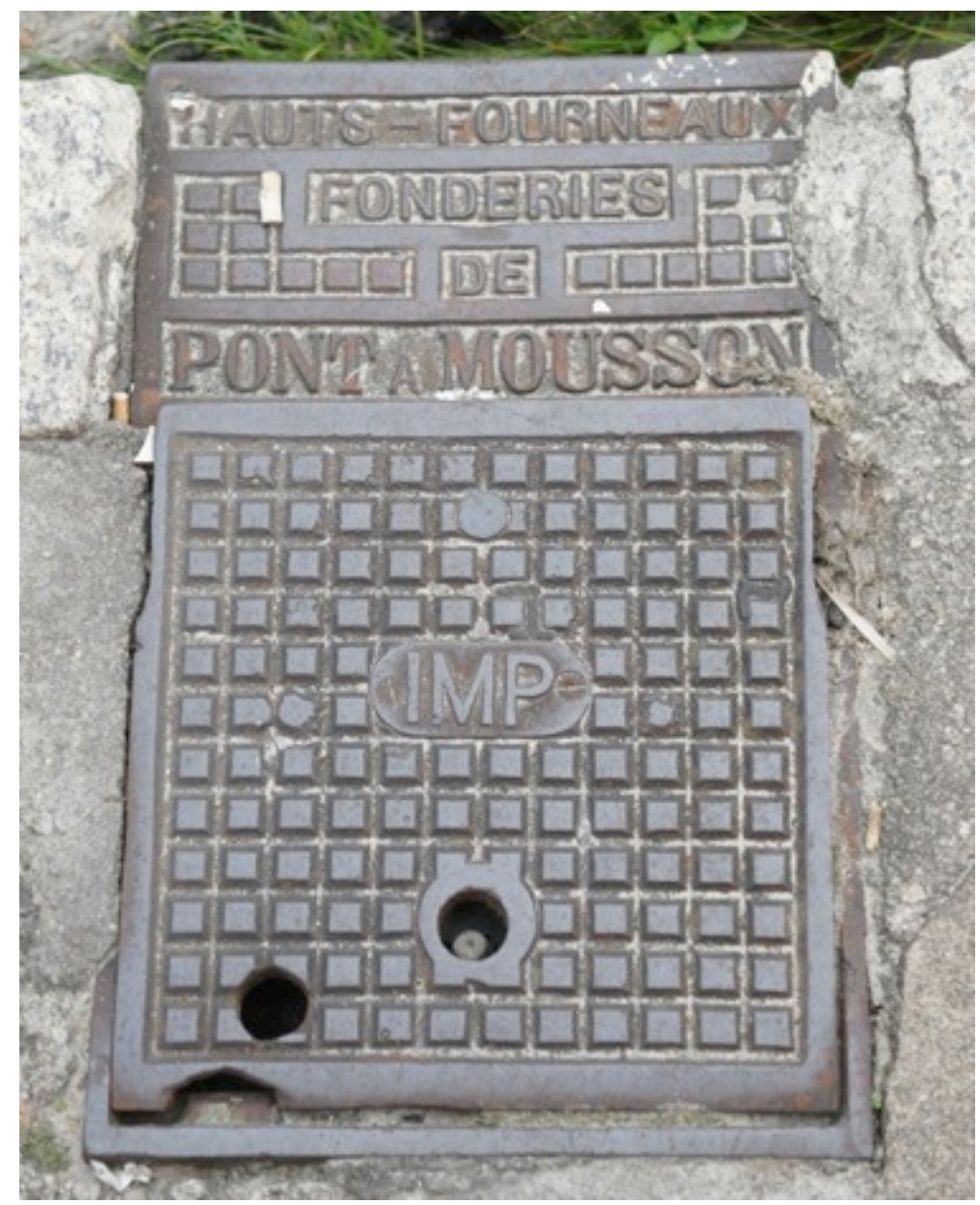


Figura 9 Tampas de esgoto e telefonia inscritas. (Fonte: Acervo da pesquisa).
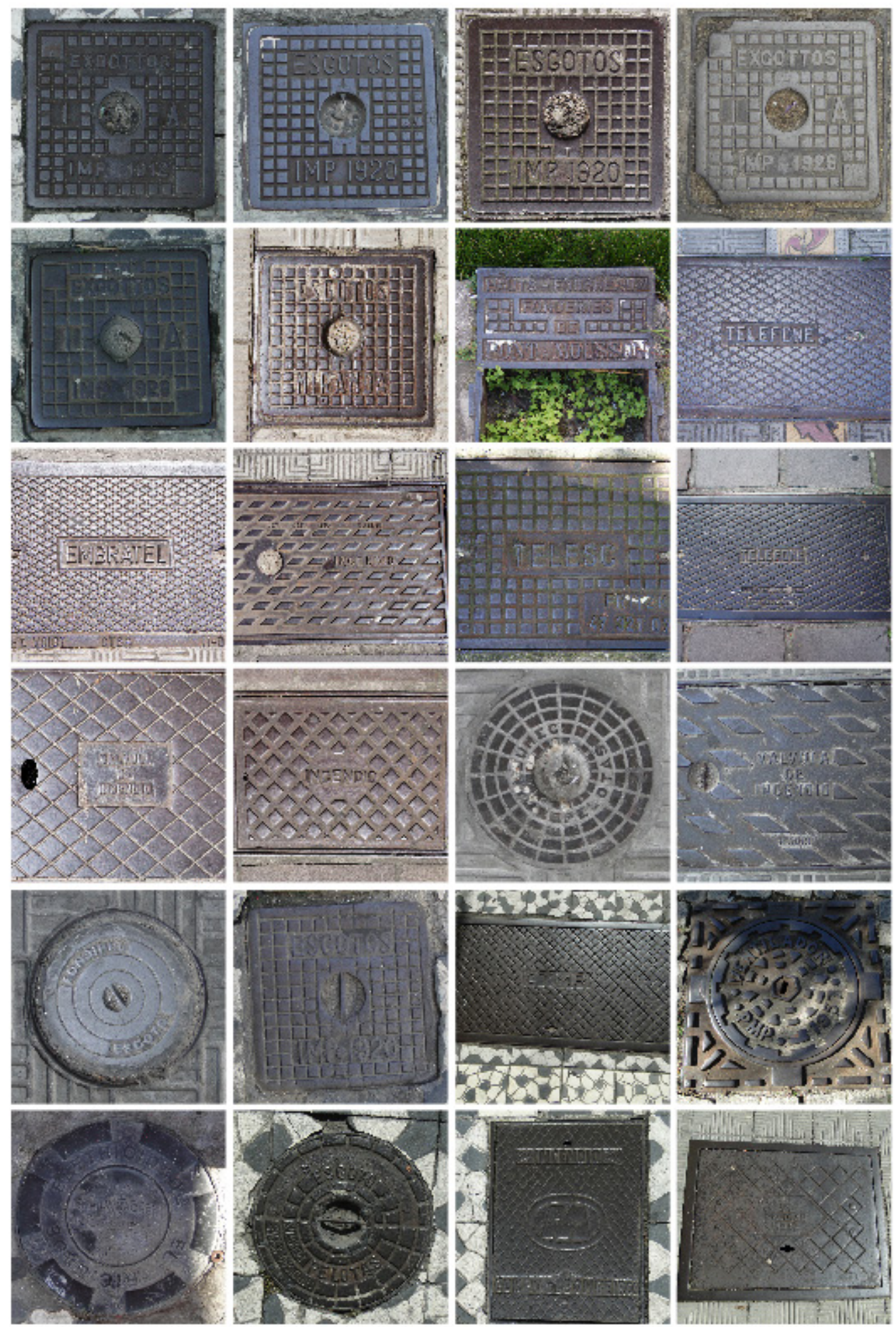

Infodesıgn || São Paulo | v. 12 | n. 2 [2015], p. 209 - 221 


\section{Levantamento do acervo e fichas catalográficas}

A partir do levantamento e seleção das imagens (Figura 10 e Figura 11), foram desenvolvidas e adaptadas, com base em Solomon et al (2009) e Langone (2012), as propostas para as fichas de catalogação e análise, que visam evidenciar, além da identificação de estilos tipográficos e características concernentes à tipografia, também os dados sobre a edificação, localização, arquitetos, construtores, empresas, materiais utilizados, usos, datas e considerações históricas. Como cada categoria detém características particulares, houve adequação nos itens definidos de modo a contemplar as necessidades descritivas de cada categoria, conforme exemplos abaixo.

A estruturação dessas fichas, ainda em fase de ajuste, pretende viabilizar a análise das ocorrências tipográficas do espaço urbano pelotense sob a perspectiva do design, identificando possíveis relações estéticas e identitárias nestes lugares muitas vezes não percebidos.

Figura 10 Ficha de catalogação - Tipografia Arquitetônica.

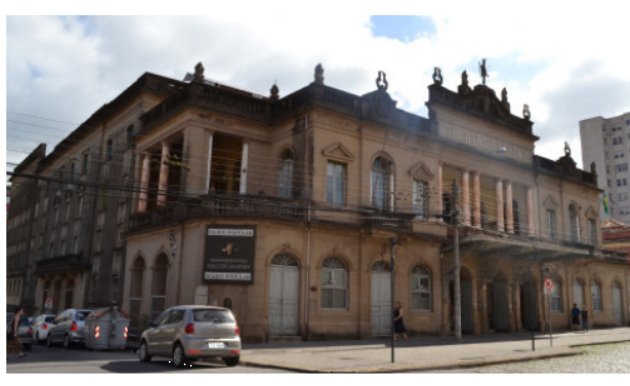

THEATRO GUARANY

Mapa de localização

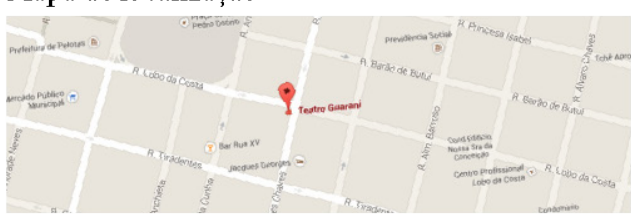

Endereço: Rua Lobo da Costa, 849

Data do projeto:

Data da construção:

Autoria do Projeto:

Estilo:

Uso Original: Teatro

Uso Atual: 'l'ealro

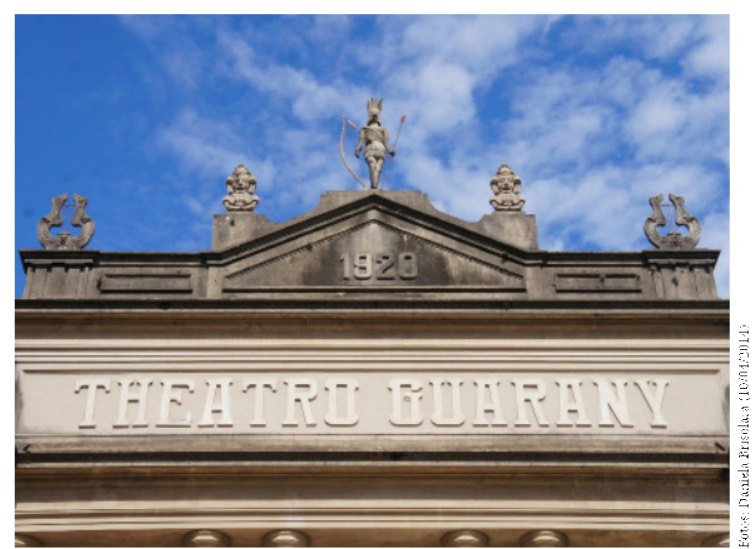

Família Tipográfica:

Peso:

Inclinação:

Alinhamento:

Material e relevo:

Tipo de Serifa:

(Ornamento): 
Figura 11 Ficha de catalogação - Tipografia de Registro (peça originária de usina de fundição francesa).

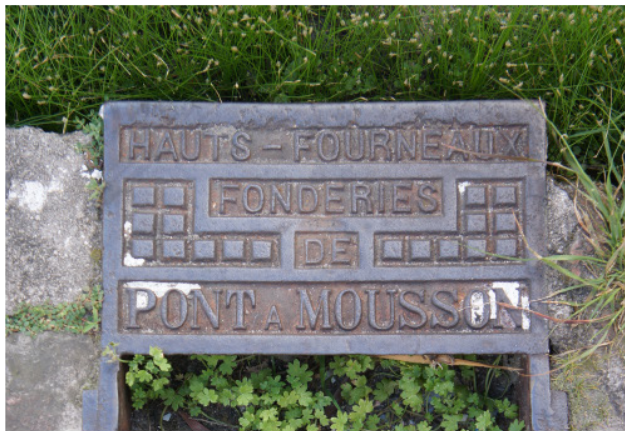

Mapa de localização

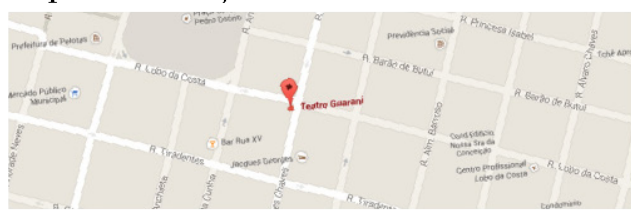

Endereço: Rua Gonçalves Chaves, 559

Data:

Empresa:

Autoria do Projeto:

Estilo:

Uso:

Material:

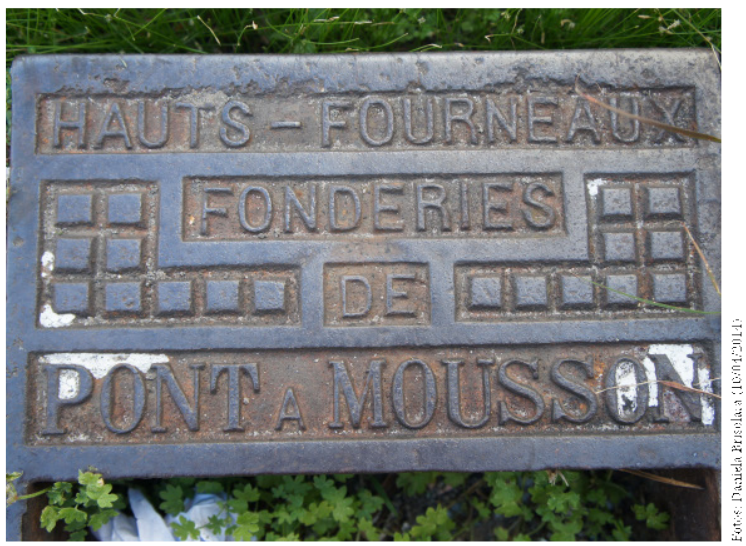

Família Tipográfica:

Peso:

Inclinação:

Alinhamento:

Material e relevo:

Tipo de Serifa:

(Ornamento):

Tipografia de Registro - Zona 2

\section{Considerações finais}

Reconhecendo-se a importância da tipografia como elemento de identidade, informação histórica e cultural e significação, o projeto de pesquisa "Paisagens Tipográficas Pelotenses: estudo exploratório sobre a tipografia no espaço urbano" surge com o intuito de identificar e classificar, em sua primeira etapa, duas das categorias de tipografias perenes presentes nos locais de preservação do patrimônio.

A pesquisa justifica-se, assim, por sua relevância histórica e memorial, além, evidentemente, dos aspectos concernentes ao design da informação, revelando dados importantes sobre a configuração visual-gráfica do ambiente construído e sobre a significação de seus elementos (tipo)gráficos. Pretende-se, neste sentido, colaborar com o quadro de pesquisas sobre 'paisagens tipográficas' que se desenvolve nos últimos anos em diversas cidades brasileiras.

Como produto resultante da primeira etapa da pesquisa têm-se a catalogação, vetorização e análise de parte da 'paisagem tipográfica pelotense', sistematizadas em acervo digital, possibilitando a troca e complementação de informações com outras pesquisas. Como continuidade e desdobramentos, a pesquisa visa a investigação das demais categorias de paisagens tipográficas pelotenses, sua sistematização em acervo digital e publicação impressa. 


\section{Referências}

BAINES, Phil \& DIXON, Catherine. Signs: lettering in the environment. London: Collins Design, 2003.

BANDEIRA, Ana da Rosa; BRISOLARA, Daniela Velleda. Das in/ex pressões em resgate a um século de Design em Pelotas: a pertinência de um estudo interdisciplinar. Anais do IV Seminário Internacional em Memória e Patrimônio: Memória, patrimônio e tradição. Pelotas: UFPel, 2010.

FARIAS, Priscila Lena; GOUVEIA, Anna P. S.; SOLOMON, Carlos X. A. Fichas de pesquisa de campo para estudo da tipografia nominativa na arquitetura carioca. InfoDesign Revista Brasileira de Design da Informação, v.6, n.2, p. 7-15, 2009.

GIBSON, David. The Wayfinding Handbook: Information Design for Public Places. New York: Princeton Architectural Press, 2009.

GOUVEIA, Anna Paula Silva; FARIAS, Priscila Lena; PEREIRA, André Luiz Tavares; GALLO, Haroldo; \& FERNANDES, Luiz Alberto. Tipografia arquitetônica paulistana: resultados de um estudo piloto. Anais do 70 Congresso Brasileiro de Pesquisa e Desenvolvimento em Design. Curitiba: AEND Brasil, 2006.

GOUVEIA, Anna Paula Silva; FARIAS, Priscila Lena; PEREIRA, André Luiz Tavares; \& BARREIROS, Gabriela. Paisagens tipográficas: lendo as letras na cidade. InfoDesign Revista Brasileira de Design da Informação, v.4, n.1, p. 1-12, 2007.

GUTIERREZ, Maria José Rocha. Design e Herança Cultural: "pensar local” para “agir global”. Dissertação de Mestrado. Universidade Técnica de Lisboa. Faculdade de Arquitetura. Lisboa, 2011.

LANGONE, Roger Leal. Inscrições Tipográficas Nominativas nos Prédios Históricos da Cidade de Pelotas/RS, Brasil. Anais do 100 Congresso Brasileiro de Pesquisa e Desenvolvimento em Design. UFMA: São Luís, 2012.

LYNCH, Kevin. A imagem da cidade. São Paulo: Martins Fontes, 1997.

NORA, Pierre. Entre memória e história: a problemática dos lugares. In: Projeto História. São Paulo, no 10, p. 7-28, dez. 1993.

\section{Sobre a autora}

\section{Daniela Velleda Brisolara,}

Mestre em Design, IFSul, Brasil <danibrisolara@pelotas.ifsul.edu.br>

Artigo recebido em 13 set. 2015,

aprovado em 21 set. 2015. 